\title{
Extração de corantes de milho (Zea mays L.)
}

\author{
Extraction of corn colorants (Zea mays L.)
}

\author{
Felix Martin Cabajal GAMARRA ${ }^{1 *}$, Gisele Costa LEME$^{2}$, Elias Basile TAMBOURGI ${ }^{1}$, Edison BITTENCOURT ${ }^{3}$
}

\begin{abstract}
Resumo
Os corantes naturais foram amplamente utilizados de forma artesanal até antes do surgimento dos corantes sintéticos. O estudo e uso dos corantes naturais voltaram a ter importância nestes últimos anos devido aos questionamentos dos organismos internacionais da saúde e dos consumidores pelo uso indiscriminado dos corantes sintéticos, ligados ao desenvolvimento de doenças degenerativas e ao impacto ambiental. O corante extraído do milho roxo (Zea mays L.) tem sido utilizado ao longo da história pela civilização Inca na preparação de alimentos e no tingimento de fibras têxteis. Neste trabalho, os pigmentos do grupo das antocianinas foram extraídos das variedades de milho roxo e do milho vermelho (Z. mays L.) e depois foram caracterizados. Três métodos de extração foram utilizados: imersão, lixiviação com algumas modificações e extração supercrítica (ESC). O melhor método para extração foi o da lixiviação que alcançou $88 \%$ (m/m) de rendimento, em função da massa do corante extraído e da matéria-prima. Também utilizando a lixiviação modificada, foi possível concentrar em $3 \%$ os compostos acilados, assim como recuperar $85 \%$ dos solventes utilizados. Um indicador de $\mathrm{pH}$ foi obtido pela fixação das antocianinas num papel de filtro, com base na estabilidade das antocianinas, ferramenta que pode ser utilizada em laboratórios de ensino de química.
\end{abstract}

Palavras-chave: antocianina; corante natural; milhos roxo e vermelho; métodos de extração; $p H$.

\begin{abstract}
Natural colorants were craftly made and widely used before the discovery of the synthetic colorants. The study and the use of natural colorants have become important again in the last few years due to questions raised by the international health organizations and consumers related to the indiscriminate use of synthetic colorants which were linked to the development of degenerative illnesses and environmental impact. The colorant extracted from purple corn (Zea Mays L.) was used by the Inca civilization to prepare food and to dye textile fibers. In this work, pigments from the anthocyanin group were extracted from purple corn and red corn (Zea Mays L.) varieties and were later characterized. Three extraction methods were used: immersion, lixiviation with some changes, and supercritical extraction (ESC). The best method of extraction was lixiviation, which reached $88 \%(\mathrm{~m} / \mathrm{m})$ of performance as a function of the mass of colorant extracted and of the raw materials. Also using the modified lixiviation it was possible to concentrate the acylate compounds in $3 \%$ as well as to recover $85 \%$ of solvent used. A pH indicator was obtained by fixing the anthocyanins on a filter paper based on anthocyanins stabilization. This technique can be utilized in laboratory chemistry lessons.

Keywords: anthocyanins; natural colorant; purple and red corn; methods of extraction; $p H$.
\end{abstract}

\section{Introdução}

O interesse em pesquisas por corantes naturais aumentou consideravelmente nas últimas décadas devido às severas críticas dos consumidores, às restrições impostas pela Organização Mundial da Saúde (OMS) e outras instituições aos corantes sintéticos. Alguns pesquisadores descrevem os diversos tipos de impactos ambientais ocasionados pela síntese e uso indiscriminado de alguns destes corantes, tais como: a poluição causada pelo descarte dos efluentes da indústria têxtil (SMITH, 1994), a contaminação dos peixes (KIRSCHBAUM et al., 2006), além dos corantes elevarem o risco das pessoas desenvolverem doenças degenerativas, como alguns tipos de câncer (BLUHM et al., 2006; WANG et al., 1997; HARTGE et al., 1982; GAGO-DOMINGUEZ et al., 2001).

As antocianinas são pigmentos pertencentes ao grupo dos compostos polifenóis, flavonoides, que é o grupo mais importante de compostos hidrossolúveis, responsáveis pelas cores que vão desde as tonalidades claras, rosa, vermelho, até tonalidades escuras, roxa, azul e preta. Estes compostos se encontram em vegetais (flores, frutos, sementes, folhas, etc.) e em animais (peixes, insetos, etc.). Segundo Harbone (1967), todas as antocianinas derivam do cátion flavílio, que é ligado aos grupos fixados sobre os anéis aromáticos (hidroxilas, entre outros), o qual é chamado de antocianina ou glicona. De acordo com Markakis (1982) e Strack e Wray (1989), o primeiro açúcar está sempre na posição 3, os outros podem ocupar diferentes posições ou ligar-se ao primeiro. Existem quantidades consideráveis de antocianinas, as quais podem ser utilizadas para os diversos fins. As descobertas das antocianinas com presença de ácidos acilados na molécula que as tornam mais estáveis aos efeitos da temperatura e do $\mathrm{pH}$, do que as antocianinas não aciladas, levaram à intensificação da procura por fontes naturais contendo estes compostos, para seu uso em alimentos (GIUSTI et al., 1998; RODRÍGUEZ-SAONA et al., 1998).

Recebido para publicação em 20/6/2007

Aceito para publicação em 28/10/2008 (002620)

${ }^{1}$ Faculdade de Engenharia Química - FEQ, Universidade Estadual de Campinas - UNICAMP, CEP 13083-852, Campinas - SP, Brasil, E-mail: gamarra@vt.edu

${ }^{2}$ Instituto de Pesquisas Tecnológicas - IPT, Estado de São Paulo S.A., Centro Tecnológico da Indústria da Moda - CETIM, CEP 05508-901, São Paulo - SP, Brasil

3 Departamento de Tecnologia de Polímeros - DTP, Universidade Estadual de Campinas - UNICAMP, CEP 13083-970, Campinas - SP, Brasil

${ }^{*}$ A quem a correspondência deve ser enviada 
Recentes pesquisas mostraram as inúmeras vantajens destes pigmentos para a saúde humana, principalmente como agente antioxidante que age na inibição dos radicais livres (TSUDA et al., 1994; WANG et al., 1999; NAM et al., 2006; PHILPOTT et al., 2006); prevenindo doenças degenerativas como o câncer (KAMEI et al., 1995; HYUN et al., 2004; ZHAO et al., 2004); melhorando a adaptação à visão noturna e prevenindo a fadiga visual (JAYAPRAKASAM et al., 2005); como anti-inflamatório (WANG et al., 1999); também foram aplicados nestes últimos anos no tratamento contra abesidade e hiperglicemia (TSUDA et al., 2003); além de serem usados como corantes de alimentos e de tecidos (TAKEOKA et al., 1997; GIUSTI et al., 1998; GAMARRA et al., 2006).

Em grãos, as altas concentrações de pigmentos de antocianinas encontram-se no pericarpo (TSUDA et al., 1994; ABDEL-AAL et al., 2006). A produção mundial de antocianinas derivadas de grãos está estimada em 10000 toneladas, e o consumo médio por pessoa, em $215 \mathrm{mg}$ durante o verão e $180 \mathrm{mg}$ durante o inverno. Isto mostra a importância das antocianinas na dieta humana e a necessidade de pesquisar, melhorar as metodologias de extração (quantificação e identificação), obter a composição e compreender a funcionalidade das fontes naturais (ABDEL-AAL et al., 2006).

As antocianinas do milho roxo (Zea mays L.) foram usadas ao longo da História pela civilização Inca na preparação de bebidas e no tingimento de fibras têxteis. Esta civilização também foi a primeira a utilizar estes pigmentos, segundo Brack-egg (1999). Eles obtinham os pigmentos de forma artesanal, utilizando processos mecânicos através de atrito e raspagem da semente. Alguns estudos mostraram o uso das antocianinas extraídas do milho roxo em combate contra o câncer de colo do útero. Este sucesso é atribuído apenas às antocianinas presentes no milho roxo (HAGIWARA et al., 2001). Outros estudos mostraram também uma quantidade significativa de fenóis presentes nas antocianinas extraídas do milho roxo, incluindo ácidos e flavonoides, que podem ser utilizados pela indústria farmacêutica (PEDRESCHI et al., 2007).

Embora existam algumas pesquisas indicando significativos avanços e benefícios das antocianinas extraídas do milho roxo, até o presente momento não se conhecem estudos sobre novas metodologias de extração destes pigmentos livres das substâncias químicas tóxicas. Como se sabe, de acordo com as tendências atuais, os consumidores exigem cada vez mais que os produtos sejam de melhor qualidade e mais saudáveis. $\mathrm{O}$ processo de extração é uma etapa crítica, pois deve preservar as características naturais do produto de origem, evitando o uso de produtos químicos em grandes quantidades que possam deixar resíduos indesejáveis no produto final. Portanto, há necessidade de se explorar esta área, assim como melhorar as metodologias de extração, melhorar os rendimentos de tal forma que estas tecnologias possam ser competitivas.

O corante em questão é um produto nobre, com alto valor agregado, apresenta grande potencial de uso nas áreas tecnológicas e comerciais, além da escassez de informações sobre o emprego de métodos de extrações. Neste trabalho, foram realizadas extrações e quantificações dos rendimentos das extrações dos corantes dos milhos roxo e vermelho provenientes do Peru utilizando os métodos da imersão, lixiviação com algumas modificiacações e a Extração Supercrítica (ESC). Também foram identificadas e quantificadas as principais antocianindinas presentes no milho por Cromatografia Líquida de Alta Eficiência (CLAE) e espectrofotometria UV-vis, assim como se obteve um indicador de $\mathrm{pH}$ através da fixação das antocianinas em papel de filtro, a partir da estabilidade das antocianinas em soluções tampões.

\section{Material e métodos}

\subsection{Material}

Foram utilizadas duas variedades nativas de milho (Zea mays L.) peruano: o roxo e o vermelho, adquiridas nas fazendas a $150 \mathrm{~km}$ ao sul de Lima, Peru, plantadas durante o ciclo agosto/ outubro. Em um solo de pH 6, condutividade elétrica de $2 \mathrm{dS} / \mathrm{m}$ e um volume de água de $8000 \mathrm{~m}^{3} /$ ha. As sementes foram selecionadas, divididas em 4 lotes (Lote $01 \mathrm{~A}$, Lote $01 \mathrm{~B}$, Lote $01 \mathrm{C} \mathrm{e}$ Lote 01D) de acordo com as características físicas (cor e densidade) para uma melhor caracterização. Todos os lotes foram embalados a vácuo em sacos de polipropileno e armazenados em congelador em temperatura em torno de $-10{ }^{\circ} \mathrm{C} \pm 2$, até o início dos ensaios. Os solventes selecionados para o trabalho foram fornecidos pela Merck (Darmstadt, Alemanha) e o $\mathrm{CO}_{2}$ pela empresa White Martins (São Paulo, Brasil). A vidraria utilizada foi de cor âmbar para proteger o corante da luz difusa e evitar sua degradação.

\section{Caracterização das sementes}

Foram selecionadas três frações de cada amostra das sementes de cada lote para a caracterização. $\mathrm{O}$ conteúdo da umidade foi calculado após as sementes terem secado em estufa a $95^{\circ} \mathrm{C}$ durante 24 horas. $\mathrm{O}$ diâmetro médio foi calculado após terem sido selecionadas 20 sementes aleatoriamente de cada lote, medidos a largura, a espessura e o comprimento e calculada a média geométrica das três medidas. $\mathrm{O}$ índice de acidez foi obtido medindo-se diretamente o pH da solução. Já o conteúdo de carboidratos, o teor de fibras e o conteúdo de minerais foram determinados pela metodologia descrita pela (AOAC, 1995).

\section{Extração e purificação das antocianinas}

As sementes foram separadas manualmente da espiga. Em seguida, foram submetidas ao processo de desidratação utilizando-se um secador do tipo ciclone (Udy, Fort Collins, $\mathrm{CO})$ com algumas adaptações, até que atingissem o teor de umidade desejada de $11 \pm 1 \%$, mantendo-se o processo a $60^{\circ} \mathrm{C}$ durante 150 minutos, com um fluxo de ar de $0,4 \mathrm{~m} / \mathrm{s}$, para evitar a degradação do pigmento. Então, separou-se manualmente o pericarpo (lugar de maior concentração dos pigmentos) do tegumento da semente. Depois, moeram-se $20 \mathrm{~g}$ de pericarpos até se obterem partículas de $0,4 \mathrm{~mm}$ de tamanho, entretanto, apenas $5 \mathrm{~g}$ foram utilizados nos processos de extração.

Extração $\mathrm{n}^{\circ}$ 1: a imersão foi realizada de acordo com a metodologia descrita por Abdel-aal et al. (2006). Esta metodologia foi modificada de acordo com as condições existentes nos laboratórios utilizados. Sendo que, foi aumentado o tempo de extração para 60 horas, diminuída a rotação para 1500 rpm a cada 4 horas, para que as moléculas a serem extraídas estabilizassem. Durante este processo, o potencial aparente da 
mistura foi ajustado até o $\mathrm{pH} 1$ e reajustado quando necessário (geralmente após 30 minutos). Os resíduos foram removidos utilizando-se o mesmo solvente da extração, até a completa remoção dos pigmentos.

Extração $n^{\circ} 2$ : teve como base a lixiviação (soxhlet), como se observa na Figura 1. O sistema manteve-se à temperatura de $55^{\circ} \mathrm{C}$ e a 1 bar de pressão durante 90 minutos, para evitar a degradação dos pigmentos. Foi adaptada uma saída na parte superior da coluna com o intuito de capturar as moléculas voláteis (solvente e soluto). Esta saída foi acondicionada a um sistema de vácuo, passando, em seguida, por um resfriamento flash $\left(1^{\circ} \mathrm{C}\right)$ em solução de etilenglicol-sal, com a finalidade de preservar os pigmentos. Posteriormente, esta alimetação foi recirculada ao sistema. A entrada desta recirculação foi de forma tangencial formando um ângulo de $45^{\circ}$ para promover uma agitação, elevar a concentração e evitar gasto de energia com sistemas de agitação. $\mathrm{O}$ pH foi reajustado com solucão tampão, quando necessário.

No fluxo de saída dos pigmentos extraídos, localizado na parte central da coluna, encontrava-se uma membrana de ultrafiltração, para aumentar a concentração do pigmento e recuperar os solventes utilizados. Esta membrana, do tipo poroso e de forma cilindro-capilar, era de polissulfona, com uma relação área/volume de $900 \mathrm{~m}^{2} / \mathrm{m}^{3}$. Esta membrana foi selecionada considerando-se as propriedades físicas dos pigmentos e dos solventes, tais como o diâmetro das partículas, as concentracões, a temperatura de ebulicão, dentre outras. Também foi considerado o diâmetro médio dos poros da membrana, sabendo-se que as partículas têm aproximadamente $0,52 \mathrm{~nm}$ e os poros da membrana têm $0,5 \mathrm{~nm}$. Utilizou-se uma velocidade de alimentação de $1.2 \mathrm{~m} \cdot \mathrm{s}^{-1}$ (9430 Reynolds).

Nos processos $n^{\circ} 1$ e 2 , utilizaram-se água deionizada, etanol, metanol, éter de petróleo, ciclo hexano e isopropanol como solventes, todos de grau analítico, adquiridos da (Merck-Clevenot Corp. Alemanha).

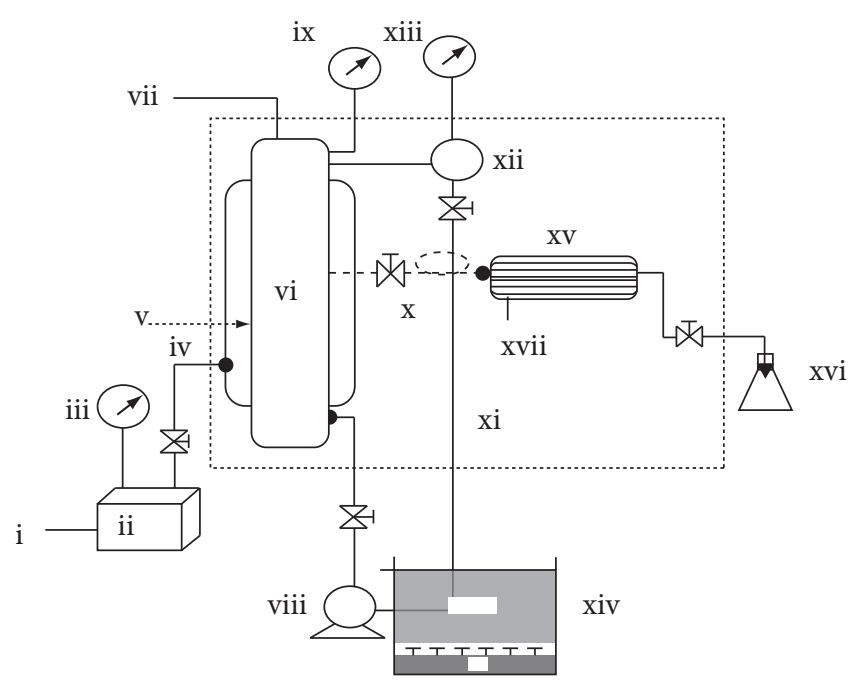

Figura 1. Sistema de extração por lixiviação. onde: i) entrada da água $\left(18^{\circ} \mathrm{C}\right)$; ii) banho de aquecimento; iii) controlador e indicador de temperatura; iv) saída da água aquecida (entrada da camisa do lixiviador); v) entrada de soluto (corante em pó); vi) coluna de lixiviação; vii) entrada do solvente; viii) bomba; ix) indicador de $\mathrm{pH}$; $\mathrm{x}$ ) saída dos pigmentos extraídos; xi) captura da mistura (solvente + soluto); xii) sistema de vácuo; xiii) indicador de pressão; xiv) banho de refrigeração; xv) sistema de membranas; xvi) recepção do extrato; e xvii) recuperação do solvente.

Já, a extração ${ }^{\circ}$ 3: foi realizada utilizando-se a Extração Supercrítica (ESC) (Figura 2). Este método consiste em explorar as propriedades críticas do $\mathrm{CO}_{2}$ (comportamento de fluido) como solvente e promover o seu contato com o soluto, utilizando-se uma forma estática de extração. Esta extração foi realizada de acordo com a metodologia descrita por Silva et al., (2006). A extração foi realizada a temperaturas de 40 e $45^{\circ} \mathrm{C}$ e pressões de 250 e 300 bar, durante 4 horas, depois de ter atingido o equilíbrio termodinâmico. Uma vez concluídas as extrações em todos os processos, duas frações de cada extrato foram retiradas e levadas à estufa a $60^{\circ} \mathrm{C}$, até a evaporação dos solventes (aproximadamente 3 horas). Em seguida, estas frações foram colocadas no evaporador rotativo $\left(40 \pm 2{ }^{\circ} \mathrm{C}\right)$ durante 15 minutos, para a remoção dos solventes utilizados. Então, uma fração obtida a cada temperatura foi esfriada em um dessecador por 12 horas, as quais foram usadas para a quantificação dos rendimentos, enquanto as outras frações foram centrifugadas $\left(20\right.$ minutos a $\left.5^{\circ} \mathrm{C}\right)$ e depois armazenadas a $-5^{\circ} \mathrm{C}$ por 48 horas, para que as moléculas de pesos moleculares maiores precipitassem e, assim, usá-las na purificação das moléculas alvo. A purificação foi realizada de acordo com o descrito por Abdel-Aal et al. (2006), através de uma nova centrifugação dos extratos brutos estocados, nas mesmas condições descritas acima. Finalmente, após as antocianinas serem centrifugadas, foram secas numa estufa com temperatura controlada sob atmosfera de nitrogênio $\left(70^{\circ} \mathrm{C}\right.$ durante 60 minutos). Os pigmentos em pó foram acondicionados em frascos de vidros cor âmbar, mantidos em um sistema de fluxo de nitrogênio, antes de serem fechados e, em seguida, armazenados sob refrigeração $\left(4^{\circ} \mathrm{C}\right)$, até o momento das análises.

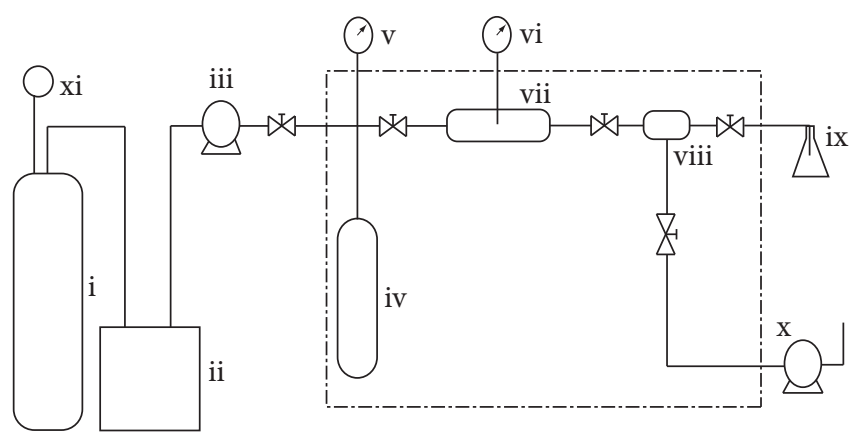

Figura 2. Sistema de extração supercrítica de forma estática. 
onde: i) cilindro de $\mathrm{CO}_{2}$; ii) banho de refrigeração; iii) bomba de altas pressões; iv) tanque pulmão de $\mathrm{CO}_{2}$; v e vi) indicador de pressão; vii) célula de equilíbrio (contato solute solvente); viii) coletor; ix) recepção do extrato; $\mathrm{x}$ ) bomba peristáltica; $\mathrm{e}$ xi) indicador de pressão.

\section{Quantificação, separação e identificação das antocianinas.}

O Conteúdo Total de Antocianinas (CTA) presente nos extratos do milho foi determinado por espectrofotometria, baseado numa adaptação ao método descrito por Abdel-Aal et al. (1999) e pela lei de Beer-Lambert. Foram colocados $3 \mathrm{~g}$ de amostra num béquer de $50 \mathrm{~mL}$, adicionados $24 \mathrm{~mL}$ de etanol acidificado (etanol e $\mathrm{HCl} 1.0 \mathrm{M}, 85: 15$, v/v) e centrifugados. Esta solução foi agitada a cada 15 minutos e o pH, ajustado até 1 , com uma solução de $\mathrm{HCl} 4 \mathrm{M}$. De acordo com a necessidade, foi armazenada por 24 horas. A solução foi centrifugada em $27200 \times$ g por 15 minutos. O sobrenadante bruto extraído foi colocado no béquer de $50 \mathrm{~mL}$ e o volume foi completado com etanol acidificado. A absorbância foi medida no espectrofotômetro UV/VIS (Milton Roy Spectronic 21 DUV UV/VIS, MA) a $535 \mathrm{~nm}$.

Uma curva de calibração foi obtida e o CTA (em micrograma por g), como mg cianidina 3-glucosida equivalente/100 g do peso seco, foi calculado utilizando-se o coeficiente absorção molar $(\varepsilon)$ de $25965 \mathrm{M}^{-1} \mathrm{~cm}^{-1}$, de acordo as Equações 1 e 2:

\section{$\mathrm{CTA}=(\mathrm{A} / \varepsilon)\left(\mathrm{vol} / 1000 \mathrm{PM}(1 / \mathrm{PA}) 10^{6}\right.$}

onde: PM é a massa molecular da cianidina 3-glucosida, 449 g.mol ${ }^{-1}$, PA é peso da amostra (neste caso 3 g) e o CTA é expresso em $(\mathrm{mg} / \mathrm{kg})$. Substituindo-se estes valores na Equação 1, chega-se à Equação 2, simplificada baseada nos princípios da Lei de Beer-Lambert:

$\mathrm{CTA}=\mathrm{A} \times 288,21 \mathrm{mg} / \mathrm{kg}$

onde: A é a absorbância, de acordo com Abdel-Aal et al. (1999).

Também o conteúdo total de antocianinas foi expresso em porcentagem de massa das sementes. Já os extratos parcialmente purificados foram utilizados na identificação das antocianinas utilizando-se a técnica da Cromatografia Líquida de Alta Eficiência (CLAE), cromatográfo modelo HP1100 (Agilent Technologies, Alemanha) de rápida resolução, formado por um injetor manual, uma bomba quaternária e um detector UV-vis, e com a temperatura controlada por uma coluna termostática. O controle do equipamento, assim como suas informações, foram obtidas da HP ChemStation (G2180AA). Foi utilizada uma coluna analítica LC-18-DB (Supelco, Inc., Bellefonte, PA) ODS/B ( $250 \times 4.6 \mathrm{~mm})$ Keystone Scientific Inc., Bellefonte, PA) com tamanho de partícula de $5 \mu \mathrm{m}$. Foram selecionadas três temperaturas, 25,35 e $50^{\circ} \mathrm{C}$ para realizar uma melhor separação e identificação das antocianinas. O solvente A contendo $10 \%$ de solução aquosa de ácido fórmico, e o solvente B contendo ácido, água e metanol (10:40:50 v/v) foram utilizados.

A separação foi realizada utilizando-se um gradiente linear de $30-90 \%$ do solvente B por 50 minutos, com uma velocidade de fluxo de $1,2 \mathrm{~mL} /$ minuto, com detecção a $525 \mathrm{~nm}$. Foi injetado um volume de $50 / \mathrm{mL}$ da amostra. Esta metodologia foi realizada de acordo com aquela descrita por Fossen et al. (2001), com algumas modificações sobre o tempo percorrido e a variação do gradiente linear. A quantificação e a identificação foram realizadas a partir da comparação dos tempos de retenção UV-vis espectro e cromatográmas com os padrões comerciais da cianidina 3-glucosida, peonidina, pelargonidina e ácido malônico Extrasynthese (Genay, França). Estes padrões foram analisados utilizando-se a mesma técnica que foi empregada para as amostras dos extratos.

\section{Obtenção do papel indicador de pH e estabilidade das antocianinas}

Foram acompanhados os perfis de estabilidade das antocianinas presentes na variedade de milho roxo e vermelho, em solução com pH 1-13, medida via espectrofotometria e colorimetria. Uma pesquisa semelhante foi realizada por Cabrita et al. (2000), na qual se utilizou a cianidina 3-glucosida. Baseada nestes estudos, surgiu a idéia de se obter papel indicador de $\mathrm{pH}$. Utilizando-se a imersão a quente $\left(55^{\circ} \mathrm{C}\right.$ por 45 minutos $)$ foram colocadas em solução $3 \mathrm{~g}$ de pó do pericarpo de milho em metanol acidificado, utilizado-se como solvente de extração a razão de $1 / 3(\mathrm{v} / \mathrm{v})$. Terminada a extração, a solução foi filtrada até a concentração de um volume em $20 \mathrm{~mL}$. Após preparar o extrato, imergiram-se as tiras de papel de filtro $\mathrm{N}^{\circ} 4$ no concentrado por 5 horas, sendo, posteriormente, secadas na estufa durante 8 horas a $45^{\circ} \mathrm{C}$. Terminada a secagem, as tiras foram colocadas em contato com as soluções tampões com pH 1-13 para se observar a mudança de cor e medir a absorbância. A mudança de cor foi medida pelo colorímetro Hunter Lab colorimeter (Color Quest 45/0, HunterLab, Reston, VA), após ser calibrado com as cores branca e preta padrão. $L^{*}$ mede a luminosidade da cor, com variacões desde $0=$ preto até $\mathrm{o} 100=$ branco; $\mathrm{a}^{\star}$ pode ter valores positivos (vermelho) ou negativos (verde) e $\mathrm{b}^{\star}$ pode ter valores positivos (amarelo) ou negativos (azul). A cor pode ser expressa em termos de L, a e b. O ângulo formado pelas 3 posições (L, a e b) foi calculado utilizando-se a expressão $\arctan (\mathrm{b} / \mathrm{a})$. A diferença de cor total $(\Delta \mathrm{E})$ foi calculada utilizando-se a seguinte Equação (3):

$\left[(\mathrm{a})^{2}+(\mathrm{b})^{2}\right]^{1 / 2}$

onde: $\Delta$ é a diferença entre o padrão e a amostra observada.

Já a leitura dos comprimentos de onda foi medida pelo espectrofotômetro UV/VIS (Milton Roy Spectronic 21 DUV UV/VIS, MA) com intervalo de medição de $250 \mathrm{~nm}$ até $700 \mathrm{~nm}$.

Todos os ensaios experimentais foram realizados em triplicata e múltiplas comparações. Também foi utilizado o teste de Duncan com múltiplos intervalos, em software SAS (SAS Institute Inc, Cary, $\mathrm{NC}$ ), tendo como critério estatístico $\mathrm{p}<0,05$, aplicado para calcular as diferenças significativas e sujeito a análises de variança. Os dados estão expressos em média $(\mathrm{M}) \pm \mathrm{e}$ desvio padrão (DP).

\section{Resultados e discussão}

A Tabela 1 mostra os valores médios encontrados durante a caracterização dos milhos roxo e vermelho, distribuídos entre 4 lotes de amostras de sementes. Não houve diferenças signi- 
ficativas nos valores encontrados para as amostras de milho vermelho e de milho roxo, mostrando que as duas variedades provavelmente derivam de um mesmo padrão que deu origem a estas variedades de híbridos.

$\mathrm{Na}$ Tabela 2, encontram-se os valores dos rendimentos médios das extrações das sementes do milho roxo, utilizandose os diferentes métodos de extração. Os valores de CTA foram determinados usando-se espectrofotômeto (faixa de $535 \mathrm{~nm}$ ), expressos em termos de porcentagens em peso do corante (principal pigmento presente na semente) com relação à massa total das sementes. Convêm lembrar que foi utilizado o pericarpo das sementes desidratadas e trituradas, atingindo-se uma umidade de $11 \pm 1 \%$, anterior ao início das extrações. Observa-se que a lixiviação foi o método mais eficiente em termos de rendimento das extrações dos corantes, obtendo-se $75 \pm 2,3$ e $88 \pm 1,1 \%$ de cianidina, quando foi utilizado o metanol como solvente. A eficiência da lixiviação foi possível devido à otimização e modificação significativa do processo, conseguindo-se aumentar a concentração de antocianinas e recuperar os solventes utilizados (aprox. 85\%).

Também se observa que os solventes orgânicos mostraram melhor capacidade de extração, o que se deve à afinidade das

Tabela 1. Caracterização das sementes dos milhos roxo e vermelho.

\begin{tabular}{lrrrrr}
\hline \multicolumn{1}{c}{ Características } & Lote & Lote & Lote & Lote & Média \pm DP \\
& 01A & 02B & 03C & 04D & \\
\hline Umidade (\% base seca) & 14,31 & 15,33 & 14,42 & 14,29 & $14,34 \pm 0,11$ \\
Diâmetro (cm) & 9,70 & 10,20 & 11,50 & 11,30 & $10,68 \pm 0,01$ \\
pH & 5,70 & 5,400 & 6,00 & 6,20 & $5,83 \pm 0,13$ \\
Carboidratos (\% peso) & 52,40 & 50,30 & 53,60 & 50,80 & $51,78 \pm 0,18$ \\
Teor de fibras (\% peso) & 2,80 & 3,20 & 3,10 & 2,90 & $3,00 \pm 0,09$ \\
Minerais (\% peso) & 0,97 & 0,99 & 0,94 & 1,10 & $1,00 \pm 0,25$ \\
\hline
\end{tabular}

Tabela 2. Porcentagem relativa dos rendimentos médios das extrações utilizando os diferentes métodos de extração.

\begin{tabular}{|c|c|c|c|}
\hline Método extração & Solvente de extração & $\begin{array}{c}\text { Rendimento }^{1} \\
\text { Valor } \pm \mathrm{DP}^{\mathrm{a}}\end{array}$ & Pigmento $^{1}$ \\
\hline \multirow[t]{6}{*}{ Imersão } & Água deionizada & $60 \pm 0,5^{\mathrm{a}}$ & $80 \pm 1,3$ \\
\hline & Etanol & $65 \pm 1,1$ & $83 \pm 2$ \\
\hline & Ciclo-hexano & $48 \pm 1,2$ & $72 \pm 0,9$ \\
\hline & Isopropanol & $55 \pm 0,96$ & $76 \pm 1,2$ \\
\hline & Éter de petróleo & $42 \pm 2,5$ & $69 \pm 1,8$ \\
\hline & Metanol & $75 \pm 2,3$ & $88 \pm 3$ \\
\hline \multirow[t]{6}{*}{ Lixiviação } & Água deionizada & $72 \pm 2,2^{\mathrm{a}}$ & $84 \pm 1,1$ \\
\hline & Etanol & $75 \pm 3$ & $88 \pm 2,8$ \\
\hline & Ciclo-hexano & $54 \pm 1,7$ & $76 \pm 2,3$ \\
\hline & Isopropanol & $63 \pm 1,4$ & $79 \pm 2$ \\
\hline & Éter de petróleo & $47 \pm 2$ & $73 \pm 2,7$ \\
\hline & Metanol & $88 \pm 1,1$ & $93 \pm 1$ \\
\hline ESC & $\mathrm{CO}_{2}$ & $7 \pm 1,9$ & $41 \pm 3,1$ \\
\hline
\end{tabular}

${ }^{1}$ Resultados expressos em valores médios \pm desvio padrão; aletras iguais indicam não haver diferença significativa ao nível de $5 \%$; e a média $\pm \mathrm{DP}=$ desvio padrão. ligações polares com as antocianinas; exceto o éter de petróleo que mostrou menor capacidade de extração, por ser um solvente extremamente volátil e de difícil controle. O metanol foi o solvente com melhor eficiência de extração das antocianinas. Já o $\mathrm{CO}_{2}$ supercrítico mostrou ser o solvente menos eficiente, atingindo apenas $7 \pm 1,9 \%$ de rendimento da extração. Os rendimentos obtidos, utilizando-se a imersão e a lixiviação, foram em alguns casos similares e em outros casos superiores, ao se comparar a extração das antocianinas do milho roxo com as do milho vermelho, assim como superiores aos encontrados por Fossen et al. (2001) e por Heinonen et al. (1998).

A Figura 3 a mostra que o nível de extração aumenta com a elevação do $\mathrm{pH} 1$ para o $\mathrm{pH} 5$ e reduz ao passar para $\mathrm{pH}$ acima de $\mathrm{pH}$ 6. Também se observou que a partir do pH 6 o comportamento do $\mathrm{pH}$ na extração é constante. Na Figura 3b, observa-se que a absorbância sofre um aumento entre 10 e 15\% quando as temperaturas são elevadas de 35 a $60^{\circ} \mathrm{C}$. Este comportamento de elevação da concentração das antocianinas também foi notado quando se trabalhou na faixa de temperaturas baixas $\left(15-25^{\circ} \mathrm{C}\right)$, embora tenha sido menos significativo do que o
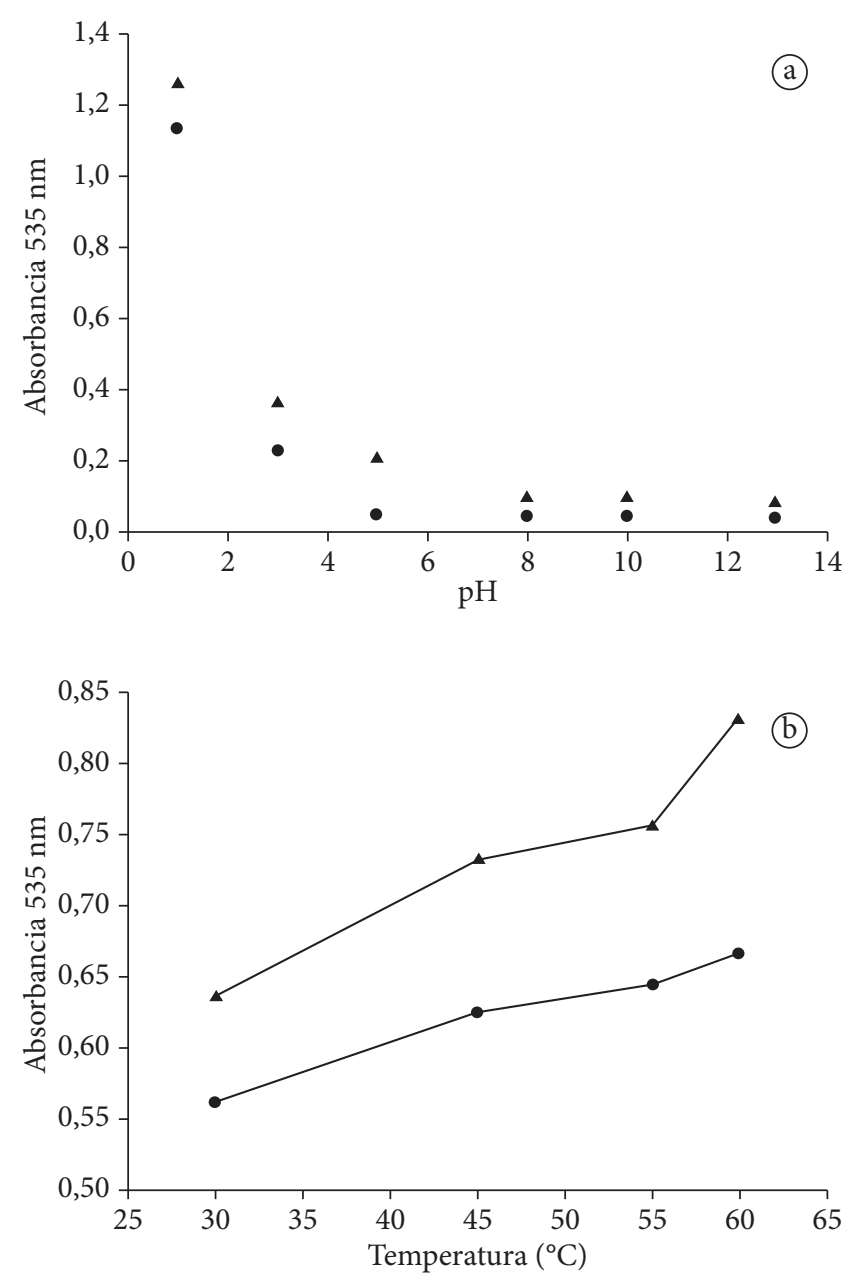

Figura 3. a) Efeito do $\mathrm{pH}$; e b) temperatura, na extração de antocianinas das sementes do milho roxo $(\bullet)$ e do milho vermelho $(\boldsymbol{\Delta})$, utilizando a imersão e metanol como solvente. 
observado para a faixa de temperaturas altas $\left(35\right.$ a $\left.60{ }^{\circ} \mathrm{C}\right)$. Este comportamento indica que a elevação da temperatura favorece a extração deste corante, porém não é indicado que se façam extrações acima de $65^{\circ} \mathrm{C}$, pois isso pode levar a um aumento na degradação do corante. Este perfil de $\mathrm{pH}$ e temperatura concorda com o perfil encontrado por Fuleki e Francis (1968b) e Abdel-Aal et al. (1999).

Na Figura 4, está mostrado o perfil cromatográfico dos extratos de milho roxo e de milho vermelho. A partir daí, foram identificadas as principais antocianinas presentes no pericarpo do milho roxo (a) e do vermelho (b), dentre elas: (1) cianidina 3-glucosida, (3) pelargonidina 3-glucosida, (4) peonidina 3-glucosida, (5) cianidina 3-(6" malonilglucosida), (6) cianidina 3-(6" etilomalonicoglucosida), dentre outras. O tempo de eluição total foi em média $60 \pm 10$ minutos em todos os cromatogramas realizados. Entretanto, os picos identificados das antocianinas aciladas (picos 5 e 8 ) tiveram um tempo de eluição de 30 minutos para o milho roxo e de 12 minutos
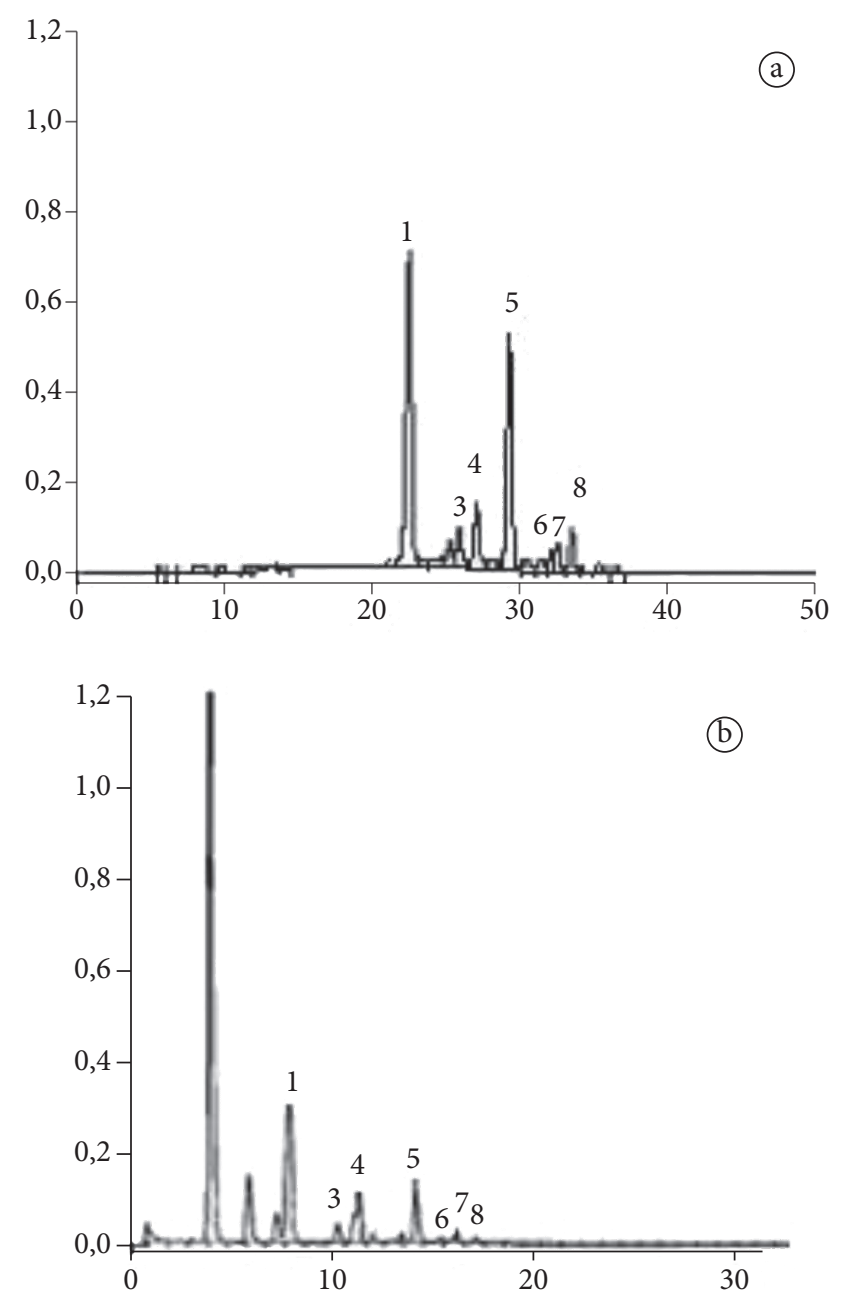

Figura 4. a) Perfil cromatográfico a $525 \pm 30 \mathrm{~nm}$ do extrato do milho roxo; e b) do milho vermelho, utilizando o método de extração por lixiviação. aproximadamente para o milho vermelho. Já os picos com presença de glicosídeos (picos 1 e 4) tiveram um tempo de eluição de 23 minutos para o milho roxo e de 9 minutos para o milho vermelho. Isto confirma a presença de ácido acilado na molécula, incrementando o tempo de retenção. O tempo de retenção é influenciado pela presença de grupos hidroxilas nas moléculas e a complexidade de substituição nos anéis B ou C, gerando uma maior mobilidade dos glicosídeos, enquanto que as moléculas com presença de grupos metoxilas diminuem o tempo de retenção, tais como as antocianinas aciladas. Os perfis cromatográficos tiveram comportamento similar em todos os casos, não sendo significativo às variações observadas. Estes perfis cromatográficos mostraram comportamentos similares aos encontrados por Drust et al. (2001), Strack e Wray (1989), Longo e Vasapollo (2005), Kallithraka et al. (2005) e Mozetic et al. (2002), embora tenham utilizado outras matérias-primas. Os cromotogramas dos extratos obtidos por lixiviação e utilizando metanol como solvente apresentaram uma significativa presença de antocianinas não aciladas. Estes concordam com os resultados encontrado por Yong e Howar (2003), os quais observaram uma menor presença de antocianinas aciladas na extração com etanol do que com metanol.

Estudos têm comprovado o efeito benéfico das antocianinas para os seres vivos. Acquaviva et al. (2003) utilizaram as antocianas na clivagem de protetores de DNA; já Tsuda et al. (1999) perceberam que as antocianinas possuem efeitos benéficos na dieta de ratos, o que também foi visto no estudo desenvolvido por Tsuda et al. (1999) e Wang et al. (2000), e notaram que as antocianinas possuem efeitos benéficos de proteção do organismo de ratos contra as toxinas da hepatite. Além destes usos, foi descoberto que os vegetais produzem as antocianinas em seus frutos como forma de preservá-los contra a oxidação e que esta atividade antioxidante varia com o estágio da fruta.

Na Tabela 3, observa-se a maior presença de antocianinas não aciladas nos extratos obtidos. No caso do milho roxo e do vermelho, observou-se uma concentração de cianidina 3 -glucosida, em porcentagens de 78 e 76,6\%, respectivamente. Também se observou a presença de compostos acilados (2,1 e $1,7 \%$, respectivamente), tais como: cianidina 3-(6" malonilglucosida, 6) e cianidina 3-(6" etilomalonicoglucosida), esta em menor participação. As porcentagens, em média, foram quantificadas por espectrofotometria em combinação com a identificação dos cromatogramas obtidos. Os extratos analisados foram obtidos da imersão, utilizando a água deionizada, etanol, ciclo-hexano, isopropanol, éter de petróleo, e metanol, como solventes.

Os valores CTA médios encontrados nos extratos obtidos após a imersão em metanol foram de $240 \mathrm{mg} / \mathrm{kg}$ para o milho roxo e de $194 \mathrm{mg} .100 \mathrm{~g}^{-1}$ para o milho vermelho. No caso da lixiviação utilizando metanol como solvente, os CTA médios dos extratos foram de $275 \mathrm{mg} .100 \mathrm{~g}^{-1}$ e $137 \mathrm{mg} .100 \mathrm{~g}^{-1}$. Já os CTA médios para os extratos obtidos após a extração supercrítica foram de $83 \mathrm{mg} .100 \mathrm{~g}^{-1}$, utilizando o $\mathrm{CO}_{2}$ supercrítico como solvente. Os valores médios obtidos dos CTA encontrados nos extratos da imersão dos milhos roxo e vermelho foram em alguns casos similares e em outros casos inferiores aos valores encontrados em antocianinas presentes em grãos pretos de sorgo 
Tabela 3. Quantificação média das principais antocianinas presentes nos milhos roxo e vermelho utilizando o método de extração por imersão.

\begin{tabular}{lccrc}
\hline & \multicolumn{4}{c}{ Variedade de milho } \\
\hline \multicolumn{1}{c}{$\begin{array}{c}\text { Porcentagem de } \\
\text { antocianinas (\%) }\end{array}$} & $\lambda(\mathrm{nm})$ & $\left.{ }_{\mathrm{M}}{ }^{+} \mathrm{H}\right]^{+}$ & Roxo & Vermelho \\
\hline Cianidina 3-glucosida & 517 & 449 & 78 & 76,6 \\
Peonidina 3-glucosida & 517 & 466 & 13,9 & 13,3 \\
Perlagonidina 3-glucosida & 502 & 430 & 6,0 & 8,4 \\
$\begin{array}{l}\text { Grupo de ácidos acilados e } \\
\text { derivados (malônico) }\end{array}$ & 517 & 540 & 2,1 & 1,7 \\
\hline
\end{tabular}

(AWIKA et al., 2004), de batata roxa (BROUILLARD, 1982), de rabanete vermelho (RODRÍGUEZ-SAONA et al., 1998) e de sementes de trigo roxo, rosa e vermelho (ABDEL-AAL et al., 1999). Enquanto que os valores de $88 \%$ de CTA e de $3 \%$ para os compostos acilados médios extraídos pela lixiviação dos milhos roxo e vermelho foram superiores aos obtidos pela imersão e que os valores encontrados nas literaturas já mencionadas, exceto aos encontrados no farelo de trigo azul que atingiu valores de $458 \mathrm{mg} / \mathrm{kg}$, obtidos por Abdel-Aal et al. (1999).

Todas as antocianinas padrões mostraram correlações lineares com as encontradas (Figura 4 e Tabela 3), com um coeficiente quadrático $\left(R^{2}\right)$ variando de 0,9831 a 0,9987 .

A Tabela 4 mostra a significativa influência do $\mathrm{pH}$ na cor das antocianinas extraídas. Observa-se que durante os primeiros contatos (antocianinas-solução tampões) com pH (1-4) as mudanças de coloração e absorbância não foram estatisticamente significativas, adotando uma cor vermelha intensa, gerada pela maior presença de compostos flavonoides. As mudanças mais significativas ocorreram no contato com soluções tampões entre pH 5-7 devido às variações de coloração (entre roxo-lilás) e ao aumento da absorbância (entre 547-564 nm). Quando se imergiu o papel em soluções tampões de pH 9-13, não se observaram varições significativas com relação à absorbância, embora se tenha percebido que se manteve o perfil de degradação da cor vermelho. Nesta faixa, houve uma tendência de comportamento estável. Segundo Brouillard (1982), estas modificações da cor são causadas pela presença do cátion flavílio, presente nas estruturas das antocianinas, que muda em direção a espécies pseudo-carbinol em meio ácido, para roxo quinoidal em meio básico. Similar comportamento foi encontrado na estabilidade das antocianinas presentes nos milhos roxo e vermelho, ao se misturar pó das cascas de sementes com as diferentes soluções tampões (na faixa de $\mathrm{pH}$ entre 1-13). O perfil encontrado foi semelhante ao encontrado por Cabrita et al. (2000) que utilizaram a cianidina 3-glucosida.

\section{Conclusões}

Este trabalho mostrou que a lixiviação com algumas modificações foi o método mais eficiente nas extrações dos corantes (aprox. 88\% de antocianinas), assim como na recuperação dos solventes (aprox. 85\%). O metanol foi o solvente mais eficiente durante a extração devido à afinidade das ligações. Os perfís cromatográficos das antocianinas extraídas para ambos os
Tabela 4. Mudança de cores do papel inserido em soluções tampões universais. ( $n=60$; teste de Duncan, tendo com critério estatístico $\mathrm{p}<0,05)$.

\begin{tabular}{ccc}
\hline Faixa de $\mathrm{pH}$ & Cor & Leitura, $\lambda(\mathrm{nm})$ \\
\hline 13 & Amarelo & - \\
$11-12$ & Verde & $575-590$ \\
$9-10$ & Azul & $568-572$ \\
$5-8$ & Roxo-Lilás & $540-560$ \\
$3-4$ & Vermelho-Laranja & $520-525$ \\
$1-2$ & Vermelho & $512-520$ \\
\hline
\end{tabular}

milhos mostraram comportamentos similares aos encontrados na literatura. Já o CTA apresentou um comportamento inverso ao perfil cromatográfico. Os CTA mostraram diferenças significativas quando comparados com as diversas variedades da mesma espécie encontradas na literatura. Estas diferenças de concentrações podem ser atribuídas à influência de fatores tais como: o clima, o cultivo e a localização dos pigmentos. Foi possível a obtenção de papel indicador de $\mathrm{pH}$, ferramenta que pode ser utilizada em laboratórios de ensaios químicos.

\section{Agradecimentos}

Agradecemos à CAPES pelo apoio financeiro; ao Sr. Maluf pela colaboração nesta pesquisa, permitindo o aceso e uso dos laboratórios e equipamentos do Instituto de Pesquisas Tecnológicas (IPT), São Paulo; ao Professor Dr. Fernando A. Cabral por permitir o uso do laboratório da Faculdade de Engenharia de Alimentos, UNICAMP; à Faculdade de Engenharia Química por permitir desenvolver esta pesquisa.

\section{Referências bibliográficas}

ABDEL-AAL, E. S. M.; HUCL, P. A rapid method for quantifying total anthocyanins in blue aleurone and purple pericarp wheats. Cereal Chemistry, v. 76, n. 3, p. 350-354, 1999.

ABDEL-AAL, E. S. M.; YOUNG. C. H.; RABALSKI, I. Anthocyanin composition in black, blue, pink, purple, and red cereal grains. Journal of Agricultural and Food Chemistry, v. 54, n. 13, p. 4696-4704, 2006.

ACQUAVIVA, R. et al. Cyanidin and cyanidin 3-O- $\beta$-D-glucoside as DNA cleavage protectors and antioxidants. Cell Biology and Toxicology, v. 19, n. 4, p. 243-252, 2003.

ASSOCIATION OF OFFICIAL ANALYTICAL CHEMISTS AOAC. Official methods of analysis. Edited by Sidney Williams. Washington, EUA, 1995.

AWIKA, J. M.; ROONEY, L. W.; WANISKA, R. D. Anthocyanins from black sorghum and their antioxidant properties. Food Chemistry, v. 90, n. 1-2, p. 293-301, 2004.

BLUHM, E. C. et al. Personal hair dye use and risks of glioma, meningioma, and acoustic neuroma among adults. American Journal of Epidemiology, v. 165, n. 1, p. 63-71, 2007.

BRACK-EGG, A.; ZEA MAYS, L. Diccionario enciclopédico de plantas útiles del Peru. 1 ed. Cuzco, Perú: Imprenta-Editorial del Centro Bartolomé de Las Casas, 1999. p. 537-538.

BROUILLARD, R. Chemical structure of anthocyanins. In: Anthocyanins as food colors. P. Markakis (Ed.). New York: Academic Press, 1982. p. 1-38. 
CABRITA, L.; FOSSEN, T.; ANDERSEN, O. M. Colour and stability of the six common anthocyanidin 3-glucosides in aqueous solutions. Food Chemistry, v. 68, n. 1, p. 101-107, 2000.

DRUST, R. W.; WROLSTAD, R. E. Separation and characterization of anthocyanins by Hplc. In: Wrolstad, R. E. (Ed.). Current Protocols in Food Analytical Chemistry. New York: John Wiley \& Sons, 2001. p. Fl 3.1-3.13.

FOSSEN, T.; SLIMESTAD, R.; ANDERSEN, O. M. Anthocyanins from maize (Zea mays) and reed canarygrass (Phalaris arundinacea). Journal of Agricultural and Food Chemistry, v. 49, n. 5, p. 2318-2321, 2001.

FULEKI, T.; FRANCIS, F. J. Quantitative methods for anthocyanins. 2. Determination of total anthocyanin and degradation index for cranberry juice. Journal of Food Science, v. 33, n. 1, p. 78-83, 1968b., 2006.

GAGO-DOMINGUEZ, M. et al. Use of permanent hair dyes and bladder-cancer risk. Internacional. Journal of Cancer, v. 91, n. 4, p. 575-579, 2001.

GIUSTI, M. M. et al. Anthocyanin pigment composition of red radish cultivars as potential food colorants. Journal of Food Science, v. 63, n. 2, p. 219-224, 1998.

HAGIWARA, A. et al. Pronounced inhibition by a natural anthocyanin, purple corn color, of 2-amino-1-methyl- 6-phenylimidazo [4,5-b] pyridine (PhIP)-associated colorectal carcinogenesis in male F344 rats pretreated with1,2- dimethylhydrazine. Cancer Letters, v. 171, n. 1, p. 17-25, 2001.

HARBORNE, J. B. The Anthocyanin pigments. In: Comparative biochemistry of the flavonoids. New York: Academic Press, 1967. p. 1-30.

HARTGE, P. et al. Use of hair dyes and risk of bladder cancer. Cancer Research, v. 42, p. 4784-4787, 1982.

HEINONEN, I. M.; MEYER, A. S.; FRANKEL, E. N. Antioxindat activity of berry phenolics on human low-density lipoprotein and liposome oxidation. Journal of Agricultural and Food Chemistry, v. 46, n. 10, p. 4107-4112, 1998.

HYUN, J. W.; CHUNG, H. S. Cyanidin and malvidin from oryza sativa $\mathrm{cv}$. heugjinjubyeo mediate cytotoxicity against human monocytic leukemia cells by arrest of G2/M phase and induction of apoptosis. Journal of Agricultural and Food Chemistry, v. 52, n. 8, p. 2213-2217, 2004.

JAYAPRAKASAM, B. et al. Insulin secretion by bioactive anthocyanins and anthocyanidins present in fruits. Journal of Agricultural and Food Chemistry, v. 53, n. 1, p. 28-31, 2005.

KALLITHRAKA, S. et al. Determination of major anthocyanin pigments in Hellenic native grapes varieties (Vitis vinifera $\mathrm{sp}$.): association with antiradical activity. Journal of Food Composition and Analysis, v. 18, n. 5, p. 375-386, 2005.

KAMEI, H. et al. Suppression of tumor cell growth by anthocyanins in vitro. Cancer Invest, v. 13, n. 6, p. 590-594, 1995.

KIRSCHBAUM, J.; KRAUSE, C.; BRÜCKNER, H. Liquid chromatographic quantification of synthetic colorants in fish roe and caviar. European Food Research and Technology, v. 222, n. 5-6, p. 572-579, 2006.

LONGO, L.; VASAPOLLO, G.; RESCIO, L. Identification of anthocyanins in Rhamnus alaternus L. Berries. Journal of Agricultural and Food Chemistry, v. 53, n. 5, p. 1723-1727, 2005.

MARKAKIS, P. Anthocyanins as food colors. New York, USA: Academic Press, 1982. 262 p.
MOZETIC, B.; TREBSE, P.; HRIBAR, J. Determination and quantification of anthocyanins and hydroxycinnamic acids in different cultivars of sweet cherries (Prunusa Vium L.) from Nova Gorica Region (Slovenia). Food Technology Biotechnology, v. 40, n. 3, p. 207-212, 2002.

NAM, S. H. et al. Antioxidative activities of bran from twenty one pigmented rice cultivars. Food Chemistry, v. 94, n. 4, p. 613-620, 2006.

PEDRESCHI, R.; CISNEROS-ZEVALLOS, L. Phenolic profiles of andean purple corn (Zea mays L.). Food Chemistry, v. 100, n. 3, p. 956-963, 2007.

PHILPOTT, M. et al. In situ and in vitro antioxidant activity of sweetpotato anthocyanins. Journal of Agricultural and Food Chemistry. v. 52, n. 6, p. 1511-1513, 2004.

RODRÍGUEZ-SAONA, L. E.; GIUSTI, M. M.; WROLSTAD, R. E. Anthocyanin pigment composition of red-fleshed potatoes. Journal of Food Science, v. 63, n. 3, p. 458-465, 1998.

SILVA, G. F. et al. Extraction of Bixin from Annatto seeds using supercritical carbon dioxide. Brazilian Journal of Chemical Engineering. Accept, 2008.

SMITH, B. Pollution prevention needs and opportunities in the textile industry. Center for Hazardous. Materials Research, 1994. In press.

STRACK, D.; WRAY, V. Anthocyanins. In: Methods in plant biochemistry. Harborne, J.B. (Ed.). London: Academic Press, 1989. v. 1, p. 325-356.

TAKEOKA, G. R. et al. Characterization of black bean (Phaseolus vulgaris L.) anthocyanins. Journal of Agricultural and Food Chemistry, v. 45, n. 9, p. 339-53400, 1997.

TSUDA, T. et al. Protective effects of dietary cyanidin 3-O- $\beta-D-$ glucoside on liver ischemia-reperfusion injury in rats. Archives of Biochemistry and Biophysics, v. 368, n. 2, p. 361-366, 1999.

TSUDA, T. et al. Absorption and metabolism of cyanidin 3-O- $\beta-\mathrm{D}-$ glucoside in rats. FEBS Letters, v. 449, n. 2-3, p. 179-182, 1999.

TSUDA, T. et al. Dietary 581 cyanidin 3-O- $\beta$-D-glucoside-rich purple corn color prevents obesity and ameliorates hyperglycemia. Journal Nutrition, v. 133, n. 7, p. 2125-2130, 2003.

TSUDA, T. et al. Antioxidative pigments isolated from the seeds of Phaseolus vulgaris L. Journal of Agricultural and Food Chemistry, v. 42, n. 2, p. 248-251, 1994.

WANG, C. J. Et al. Protective effect of Hibiscus anthocyanins against tert-butyl hydroperoxide-induced hepatic toxicity in rats. Food and Chemical Toxicology, v. 38, n. 5, p. 411-416, 2000.

WANG, F. et al. Properties of anthocyanins from grape cell culture. Journal of Food Science, v. 62, n. 2, p. 246-248, 1997.

WANG, H. et al. Antioxidant and anti-inflammatory activities of anthocyanins and their aglicons, cyanidin, from a tart cherries. Journal of Natural Products, v. 62, n. 2, p. 294-296, 1999.

YONG, J. Z.; HOWAR, L. R. Effects of solvent and temperature on pressurized liquid extraction of anthocyanins and total phenolics from dried red grape skin. Journal of Agricultural and Food Chemistry, v. 51, n.18, p. 5207-5213, 2003.

ZHAO, C. et al. Effects of commercial anthocyanin-rich extracts on colonic cancer and nontumorigenic colonic cell growth. Journal of Agricultural and Food Chemistry, v. 52, n. 20, p. 6122-6128, 2004. 